17. Zhong W., Wang G., Zhou Q. et al. Spatial niche partitioning of coexisting small mammals in sand dunes // Italian Journal of Zoology. 2016. Vol. 83, № 2. P. 248-254. DOI: 10.1080/11250003.2016.1139636.

18. Puan C. et al. Understanding of relationships between ground cover and rat abundances: An integrative approach for management of the oil palm agroecosystem [El. resource] // http://sciencedirect.com/science/article/ pii/S0261219411002031.

19. Goodin D.G., Koch D.E., Owen R.D. et al. Land cover associated with hantavirus presence in Paraguay //
Global Ecology and Biogeography. 2006. Vol. 15, Is. 5. P. 519-527.

20. Root J.J., Calisher C.H., Beaty B.J. Relationships of deer mouse movement, vegetative structure, and prevalence of infection with Sin Nombre virus // Journal of Wildlife Diseases. 1999. Vol. 35 (2). P. 311-318.

21. Palma R.E., Polop J.J., Owen R.D. et al. Ecology of rodent-associated hantaviruses in the southern cone of South America: Argentina, Chile, Paraguay, and Uruguay // Journal of Wildlife Diseases. 2012. Vol. 48, № 2. P. 267-281. DOI: 10.7589/0090-3558-48.2.267.

\title{
ASSOCIATION OF SMALL MAMMAL'S SPATIAL DISTRIBUTION AND VEGETATION COVER STRUCTURE (ON THE EXAMPLE OF PUSTYN CLOSED WOOD, NIZHNY NOVGOROD REGION)
}

(C) 2019

Boryakova Elena Evgenievna, candidate of biological sciences, associate professor of Botany and Zoology Department

National Research Lobachevsky State University of Nizhny Novgorod (Nizhny Novgorod, Russian Federation)

Abstract. The following paper deals with the problem of spatial distribution of mouse-like rodents in connection with a vegetable cover character. Small mammals are studied as components of the whole system - biocenosis. The investigation was carried out during the summer of 2016 in the landscape protected area Pustyn located in the province of Nizhny Novgorod, Volga Upland. 6 sample plots were set up in different forest types. Micromammalia were trapped using a traditional method, over standard sample plots $(20 \times 20 \mathrm{~m})$ in a random order. 226 animals were caught, they turned out to belong to 2 genera and 3 species: Cletrionomys glareolus Schreber, Apodemus flavicollis Melchior, Apodemus uralensis Pallas. Statistical analysis was fulfilled using Statistica 6.0 software suite. We used a nonparametric Spearman method for calculation of correlations. The Principal Component Analysis (PCA) was used for detection of groups of similar objects, to reduce the number of dimensions and for visualization of the results. Positive and negative correlation dependences between the number of micromammalia and abundance of separate species of plants are revealed. The PCA analysis has shown that there is a significant factor for spatial distribution of small mammals, which is positively connected with nitrogen-loving plants. Rodents generally prefer places where projective cover degree of vegetation makes about $60 \%$. This value is possibly optimum for movement and holes digging; the shortage of food is possible when the covering indicators are smaller and the density of animal's population is big. The bank vole shows ecological plasticity in the choice of habitats more than mice. Based on results of our research, it is possible to conclude that heterogeneity of a vegetation cover has an influence on spatial structure of micromammalia communities.

Keywords: small mammals; vegetation cover; Nizhny Novgorod Region; Volga Upland; Pustyn National Park; pygmy wood mouse; yellow-necked mouse; bank vole; codominant; Spearmen correlation; principal components analysis; scatterplors; spatial structure of micromammalia communities.

\section{ЭКОЛОГИЧЕСКАЯ ОЦЕНКА РЕГЕНЕРАЦИОННЫХ СПОСОБНОСТЕЙ МИКРОФАУНИСТИЧЕСКОГО КОМПЛЕКСА ПОЧВЕННЫХ БЕСПОЗВОНОЧНЫХ В УСЛОВИЯХ РЕКУЛЬТИВАЦИИ ТЕХНОГЕННО ТРАНСФОРМИРОВАННЫХ СВЕТЛО-СЕРЫХ ЛЕСНЫХ ПОЧВ}

(C) 2019

\author{
Вершинина Ирина Валерьевна, кандидат биологических наук, \\ доцент кафедры экологического образования и рационального природопользования \\ Козлов Андрей Владимирович, кандидат биологических наук, \\ доцент кафедры экологического образования и рационального природопользования \\ Нижегородский государственный педагогический университет имени Козьмы Минина \\ (2. Нижний Новгород, Российская Федерация)
}

\footnotetext{
Аннотаџия. В работе представлены результаты исследования по экологической оценке техногенного воздействия на численность микрофаунистического комплекса почвенных беспозвоночных в условиях природного лугового биоценоза. Основной целью работы была оценка влияния рекультивационных мероприятий на регенерационные процессы сообщества микрофауны в условиях техногенно трансформированных почв. Данные исследования осуществлены на серых лесных легкосуглинистых почвах Нижегородской области. Учет микроартропод проводили в соответствии с методами, принятыми в почвенной зоологии с последующей экстракцией в лаборатории по методу Тульгрена-Берлезе с подогревом электролампами. С целью оценки общей численности микрофаунистического комплекса нарушенных почв было проанализировано более
} 


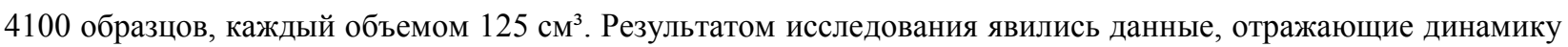
изменения численности населения представителей орибатид и коллембол в условиях антропогенно нарушенных почв. Установлено, что механическое нарушение почвы приводит к резкому снижению численности микроартропод вследствие изменения эдафических факторов почвенной среды обитания. В условиях техногенного воздействия плотность микрофауны составляет 17 экз./м². Максимально высокое значение численности мелких почвенных беспозвоночных было установлено в 2018 г. Подчеркивается, что увеличение численности мелких почвообитающих наиболее интенсивно происходит в варианте с частичной рекультивацией.

Ключевые слова: техногенно нарушенные почвы; микрофауна; педобионты; почвенные беспозвоночные; микроартроподы; коллемболы; биотоп; биоценоз; орибатиды; регенерационный процесс; почвенные беспозвоночные; рекультивационные мероприятия; вертикальное распределение организмов; устойчивость почвенной экосистемы.

\section{Введение}

Преобразование природной среды, обусловленное традиционным способом использования земель и возрастающим техногенным воздействием, требует постоянных мониторинговых наблюдений за компонентами окружающей среды и анализа экологических последствий различных форм антропогенного влияния. В условиях стремительного развития линейных сооружений на территории Российской Федерации, значительные площади вовлекаются в зону негативного влияния физического, механического и химического воздействия, следствием чего являются нарушения сложения почвенного профиля и изменения в физико-химических и питательных свойствах почвы. Часто встречающиеся нарушения почв представлены их физико-химической деградацией, перемешиванием гумусо-аккумулятивного горизонта с нижележащими слоями вплоть до полного нарушения генетически сложившегося чередования почвенных горизонтов [1]. При планировании и организации мероприятий по рекультивации таких техногенно трансформированных почв значительный интерес представляет оценка влияния степени трансформации на биотический компонент экосистемы и возможности оптимизации почвенных условий среды с помощью рекультивационных мероприятий.

Почва является естественной средой обитания беспозвоночных животных, она определяет спектр экологических условий, которые формируют питательный субстрат и координируют возможность их естественного существования в условиях конкретного биотопа. Воздействие химических свойств почвы на жизнеобеспечение педобионтов и их разнообразие осуществляется преимущественно через почвенную кислотность, которая имеет двойное воздействие на процесс осморегуляции, а также на качество и динамику многообразия питательных источников [2]. Кроме того, важнейшими параметрами почвы, определяющими функциональную стабильность зооценоза, являются ее гранулометрические свойства, водный и окислительно-восстановительный режимы, а также наличие в ней базиса питательных веществ в виде легкодоступного органического вещества и состав произрастающего фитоценоза [3]. В частности, составу последнего Григорьева придает важнейшее значение [4], считая его основным фактором формирования фауны беспозвоночных, который перекрывает влияние различных почвенных и зональных условий. Кроме того, влияние растительного покрова сказывается в большей мере на динамике мелких беспозвоночных, однако определяющим фактором в регуляции численности почвообитающей энтомофа- уны выступает содержание специфического органического вещества - гумуса [5].

В настоящее время перечень почвенных характеристик, необходимых для жизнеобеспеченности почвообитающей биоты, находящейся под влиянием различных природных [6-8] и антропогенных воздействий [9-14], существенно расширен. Сюда включены такие физические свойства почв как естественная плотность и степень эродированности дневных горизонтов, почвенный редокс-потенциал, качественный состав микроэлементов и количество легкорастворимых солей натрия, калия и алюминия, динамика обменных катионов в почвенном растворе, содержание радионуклидов, органических поллютантов, тяжелых металлов и мышьяка, а также ферментные показатели микробного пула почв.

Педобионты очень чувствительны к разнообразным трансформациям во внутрипочвенной среде, что определяет их в качестве биологических индикаторов степени трансформации и нарушенности почвенно-биотического комплекса биогеоценозов [1520]. Такие показатели как видовое разнообразие, численность и биомасса беспозвоночных животных, связанных с почвой определенным периодом онтогенеза, относят к наиболее значимым с точки зрения почвенной биологии. Наряду с динамикой флоры и отдельными группами почвенного микробиоценоза [21; 22] почвообитающие беспозвоночные животные являются биологическими тест-объектами при определении степени загрязнения в зоне влияния промышленных комплексов, качественных показателей почвенного покрова и направленности изменения их в результате техногенных преобразований и деградационных процессов.

Целью нашей работы явилось исследование состава и численности микроскопического комплекса беспозвоночных животных на техногенно нарушенных почвах при их самовосстановлении и использовании рекультивационных мероприятий.

Объектами исследования являлись почвенные беспозвоночные - представители микрофаунистического комплекса (коллемболы и орибатиды) в условиях самовосстановления фитоценоза и рекультивации техногенно нарушенной светло-серой лесной почвы.

\section{Материалы и методика исследований}

Территория проведения исследования - местность в центральной части Нижегородской области. Рассматриваемая часть области относится к Нечерноземной зоне Европейской части России, расположена в Средне-Русской провинции южной подзоны таежно-лесной зоны и по климатическому делению относится к IV агроклиматическому району - уме- 
ренно теплому, занимающему большую часть Правобережья Нижегородской области [23]. Во время проведения исследований химические свойства исследуемых почв были представлены средним содержанием гумуса (от 1,3\% до 2,9\%), повышенным содержанием подвижных соединений фосфора (110 мг/кг) и калия (157 мг/кг); гидролитическая кислотность почвы более 2,5 мг-экв./100 г почвы.

Исследования численности микроартропод осуществляли с мая по октябрь в течение трех сроков при учете сезонной активности данных организмов. Отбор почвенных монолитов для учета числа микроартропод производили на стационарных участках пробоотборником (объем $125 \mathrm{~cm}^{3}$ ), количество точек - 15, глубина отбора - 0-5 см и 5-10 см. Далее почвенных беспозвоночных извлекали из образцов в лабораторных условиях по методу Тульгрена-Берлезе путем прогревания почвенного монолита. Выделенные микроартроподы сохраняли в спиртоглицериновой смеси.

Исследование динамики численности микроартропод осуществляли в условиях естественного многолетнего разнотравного лугового ценоза (вариант «Контроль»). На данном участке выделяли два участка полосы отвода магистрального трубопровода с шириной в 14 м [24]. В начале летнего сезона 2010 года на двух участках (вариант 2 - «НП-НП» и вариант 3 - «НП-Рекультивация») были проведены строительно-монтажные работы по ремонту нефтепровода, вследствие чего произошло уничтожение естественной растительности и нарушение естественного сложения почвы. В конце июня на данных участках был осуществлен технический этап рекультивации, в заключительной стадии которого на одном из участков (вариант 3) была внесена доломитовая мука в дозе 4 т/га для оптимизации почвенной кислотности и улучшения условия для восстановления естественного фитоценоза. В 2011 году на участке варианта 2 снова выполнялись строительные работы, что привело к повторному механическому нарушению восстанавливающейся почвы и деградации фитоценоза на этапе однолетнего самозаростания. В дальнейшем данные участки механическому нарушению не подвергались.

Математическую обработку полученных данных проводили методом вариационного анализа (расчет среднего арифметического (М) и стандартного отклонения (m)) с использованием программного пакета Microsoft Office Excel.

\section{Результаты исследований и их обсуждение}

Изучение микроскопического комплекса беспозвоночных животных техногенно трансформированной почвы сопровождалось оценкой изменения численности и плотности микроартропод, а также исследованием вертикального распределения мелких почвообитающих беспозвоночных организмов по 10сантиметровому слою почвы. Данные, отражающие количественную характеристику микроартропод приведены в табл. 1. Наиболее углубленному изучению были подвергнуты ногохвостки, являющиеся пионерами заселения нарушенных почв. Для данной группы организмов были определены жизненные формы в соответствии с классификацией С.К. Стебаевой (1970).

Контрольный вариант характеризовался максимально высокой плотностью заселения микроартроподами. Численность микрофаунистического комплекса в условиях лугового ценоза на протяжении всех лет исследования изменялась незначительно. Наибольшее число мелких беспозвоночных было отмечено в 2018 году, при этом минимальное количество микроартропод было зафиксировано в 2010 г. и в 2017 г. Снижение общего числа микроскопических беспозвоночных животных в 2010 г. было обусловлено засушливым летним периодом, а в 2017 г. наоборот, процессом переувлажнения почвы и низких температур в июне месяце.

Структурная организация микроскопического фаунистического комплекса, представленная в табл. 2, была представлена орибатидами $(\mathrm{O})$ и коллемболами (К). В составе микроартропод естественного ненарушенного натурбиогеоценоза доминировали панцирные клещи. Орибатиды доминировали над коллемболами в своей численности на протяжении всех лет исследования, что очевидно свидетельствует о повышении устойчивости изучаемого биотопа.

В условиях нарушения почвенного покрова (вариант 2, вариант 3) общее количество мелких членистоногих резко сократилось. Непосредственно в год нарушения (2010 г.) на варианте 2 было зафиксировано лишь 17 экз./м² представителей микрофауны, при этом более $70 \%$ из них составляли коллемболы, тогда как средняя численность почвенных клещей была минимальна. На основании этого можно однозначно предположить, что деградация естественного фитоценоза и механическое нарушение естественного сложения почвы приводило к гибели исходного микрофаунистического комплекса.

Таблица 1 - Средняя численность мелких почвообитающих беспозвоночных в исследуемой техногенно нарушенной почве, экз./м²

\begin{tabular}{|l|c|c|c|c|c|}
\hline \multirow{2}{*}{\multicolumn{1}{c|}{ Вариант }} & \multicolumn{5}{|c|}{ Годы проведения исследований $(\mathrm{M} \pm \mathrm{m})$} \\
\cline { 2 - 6 } & 2010 г. & 2011 г. & 2012 г. & 2017 г. & 2018 г. \\
\hline Контроль & $25032 \pm 1234$ & $25359 \pm 1327$ & $26869 \pm 879$ & $25165 \pm 1121$ & $26342 \pm 1523$ \\
\hline НП - НП & $17 \pm 3$ & $11 \pm 2$ & $37 \pm 7$ & $456 \pm 23$ & $1324 \pm 214$ \\
\hline НП - Рекультивация & $125 \pm 15$ & $548 \pm 67$ & $1526 \pm 316$ & $7213 \pm 1324$ & $10528 \pm 3245$ \\
\hline
\end{tabular}

Таблица 2 - Средняя плотность представителей микрофаунистического почвенного комплекса, экз./м²

\begin{tabular}{|c|c|c|c|c|c|c|c|c|c|c|}
\hline \multirow{2}{*}{ Вариант } & \multicolumn{2}{|c|}{2010 г. } & \multicolumn{2}{|c|}{$2011 \Gamma}$. & \multicolumn{2}{|c|}{2012 г. } & \multicolumn{2}{|c|}{2017 г. } & \multicolumn{2}{|c|}{2018 г. } \\
\hline & $\mathrm{O}$ & $\mathrm{K}$ & $\mathrm{O}$ & $\mathrm{K}$ & $\mathrm{O}$ & $\mathrm{K}$ & $\mathrm{O}$ & $\mathrm{K}$ & $\mathrm{O}$ & $\mathrm{K}$ \\
\hline Контроль & 14793 & 10239 & 14094 & 11265 & 15324 & 11545 & 14797 & 10368 & 14990 & 11352 \\
\hline НП - НП & 5 & 12 & 3 & 8 & 7 & 30 & 113 & 343 & 154 & 1170 \\
\hline НП - Рекультивация & 11 & 114 & 196 & 352 & 283 & 1243 & 1523 & 5720 & 1723 & 8805 \\
\hline
\end{tabular}


Вторичное нарушение почвенного покрова и растительности в 2011 году на варианте 2 негативным образом сказалось на численности популяции микрофаунистического сообщества. Установлено, что плотность микроартропод в 2011 г. по отношению к 2010 г. снизилась на $35 \%$. Через год после очередного нарушения (2012 г.) на фоне интенсивного развития растительного покрова на варианте 2 численность микроартропод возросла, ее плотность увеличилась более чем в 3 раза и составила 37 экз./ $\mathrm{M}^{2}$. Тем не менее, показатели плотности почвенного населения на нарушенных участках варианта 2 даже к 2012 году были ничтожно малы по отношению к контрольному варианту. Через 5 лет после последнего нарушения в трансформированном почвенном покрове были обнаружены коллемболы и орибатиды в количестве 456 экз./ $\mathrm{M}^{2}$. Наибольшую долю (более $70 \%$ в комплексе микроартропод варианта 2 составляли коллемболы, а их максимальное количество было выявлено в 2018 году. Несмотря на увеличение общего числа микроартропод, можно говорить о том, что механическое нарушение почвенного покрова привело к формированию неблагоприятных факторов почвенной среды для жизнедеятельности мелких почвенных беспозвоночных.

Частичный этап биологической рекультивации (внесение доломитовой муки) на варианте 3 способствовал оптимизации внутрипочвенных условий кислотно-основного баланса, что положительным образом отразилось на численности фауны мелких беспозвоночных, плотность которых постепенно возрастала. Уже в 2010 году на варианте с рекультивацией была зафиксирована относительно высокая плотность микроартропод, которая превышала аналогичный показатель для нарушенного участка варианта 2 в 7,4 раза. Через год после проведения биологического этапа рекультивационных мероприятий численность микрофауны повысилась в 4,4 раза по отношению к предыдущему году.

В течение всех лет исследования в варианте 3 в группировке микроатропод доминировали коллемболы, при этом следует отметить значительный рост численности орибатид в 2011-2018 гг. В отсутствии повторного нарушения почвенного и растительного покровов, и использования приема биологической рекультивации в 2011 году плотность популяции панцирных клещей была в 17 раз выше, чем в 2010 году на этом же варианте. Также отмечается, что общий рост числа микрофауны в 2012 году на варианте 3 происходил преимущественно за счет резкого увеличения количества коллембол, их численность по сравнению с 2011 годом увеличилась в 3,5 раза. Сoотношение коллембол и орибатид в составе микроатропод варьировало незначительно при постоянном ярко выраженном доминировании ногохвосток. На основании проанализированных данных, можно отметить тенденцию увеличения численности микрофаунистического комплекса для двух нарушенных вариантов в 2017-2018 гг. Установлено, что на варианте 3 восстановление численности микроартропод происходило значительно интенсивнее, чем на варианте 2 , однако даже при условии частичной рекультивации регенерационные процессы, происходящие в микрофаунистическом почвенном комплексе не позволили восстановится сообществу мелких почвенных беспозвоночных до уровня контрольного варианта (ненарушенной почвы).

Изучение вертикального распределения мелких беспозвоночных животных по почвенному горизонту до глубины 10 см (табл. 3) показало, что наибольшее количество организмов находится в слое $0-5 \mathrm{~cm}$. Тем не менее, следует отметить, что слой 5-10 см на вариантах лугового ценоза был густо заселен микроартроподами.

Вследствие нарушения почвенно-растительного покрова первопоселенцы (коллемболы), освоили и заселили только верхний слой техногенно преобразованной почвы (0-5 см). Далее в 2012 году, когда отсутствовало техногенное воздействие на почву и самовосстанавливающийся фитоценоз, на варианте 2 микроартроподы начинают заселять слой 5-10 см. В условиях проведенной рекультивации (вариант 3) пионерная группировка микрофауны начинает заселять слой почвы вплоть до 10 см. К 2018 году вариант 2 и вариант 3 характеризовались тенденцией к увеличению численности коллембол на глубине 5$10 \mathrm{~cm}$, при этом количество микроартропод населяющих горизонт 5-10 см было значительно выше на варианте с рекультивацией.

Основные пионеры заселения (коллемболы) были идентифицированы в виде геми- и эуэдафических форм, в первой из которых были выделены нижнеподстилочные и подстилочнопочвенные формы, а во второй группе - верхнепочвенные и глубокопочвенные. Все представители данных форм встречались на глубине $0-10 \mathrm{~cm}$. На контрольном варианте доминировали верхнеподстилочные формы, составляя более $50 \%$ от общего числа всех организмов. Второй по численности группой на контрольном варианте натурбиогеоценоза являлись гемиэдафические подстилочнопочвенные формы. Нарушение почвы привело к развитию подстилочнопочвенных форм, тогда как эуэдафические формы были угнетены практически полностью. Рекультивация способствовала увеличению численности гемиэдафических подстилочнопочвенных форм коллембол. Самовосстановление биоценоза (вариант 2) сопровождалось постепенным изменением соотношения найденных форм ногохвосток, однако даже к 2018 году их состав отличался от контрольного варианта.

Таблица 3 - Распределение представителей микрофаунистического комплекса по почвенному профилю $(0-10 \mathrm{~cm})$

\begin{tabular}{|l|c|c|c|c|c|c|c|c|c|c|}
\hline \multirow{2}{*}{ Вариант } & \multicolumn{2}{|c|}{2010 г. } & \multicolumn{2}{c|}{2011 г. } & \multicolumn{2}{c|}{2012 г. } & \multicolumn{2}{c|}{2017 г. } & \multicolumn{2}{|c|}{2018 г. } \\
\cline { 2 - 14 } & $\mathrm{O}$ & $\mathrm{K}$ & $\mathrm{O}$ & $\mathrm{K}$ & $\mathrm{O}$ & $\mathrm{K}$ & $\mathrm{O}$ & $\mathrm{K}$ & $\mathrm{O}$ & $\mathrm{K}$ \\
\hline \multirow{2}{*}{ Контроль } & $\frac{11564}{3229}$ & $\frac{7361}{2878}$ & $\frac{11096}{2998}$ & $\frac{8279}{2986}$ & $\frac{12177}{3147}$ & $\frac{7921}{3624}$ & $\frac{11532}{3265}$ & $\frac{7114}{3254}$ & $\frac{11982}{3008}$ & $\frac{8338}{3014}$ \\
\hline \multirow{2}{*}{ НП - НП } & $\underline{5}$ & $\frac{12}{0}$ & $\underline{3}$ & $\underline{8}$ & $\underline{6}$ & $\frac{24}{6}$ & $\frac{101}{12}$ & $\frac{325}{18}$ & $\frac{135}{19}$ & $\frac{1114}{56}$ \\
\hline \multirow{2}{*}{ НП - Рекультивация } & $\frac{11}{0}$ & $\frac{112}{2}$ & $\frac{192}{4}$ & $\frac{337}{15}$ & $\frac{273}{10}$ & $\frac{1220}{23}$ & $\frac{1467}{56}$ & $\frac{5600}{120}$ & $\frac{1655}{68}$ & $\frac{8673}{132}$ \\
\hline
\end{tabular}

Примечание. Значение над чертой - слой почвы 0-5 см, значение под чертой - слой почвы 5-10 см. 


\section{Bulвodbl}

На основании проведенного экологического мониторинга почвообитающих беспозвоночных установлено, что нарушение почвенно-растительного покрова приводит к резкому снижению численности мелких членистоногих-педобионтов. В составе микроартропод наиболее уязвимой группой являются панцирные клещи, восстановление числа которых происходит существенно медленнее, чем коллембол. Заселение нарушенных почвенных горизонтов происходит преимущественно с верхнего слоя (0-5 cм) гемиэдафическими подстилочнопочвенными формами коллембол. Основной доминирующей группой мелких почвенных беспозвоночных в нарушенных почвах лугового ценоза являются ногохвостки. Рекультивация нарушенных земель оказывает положительный эффект на обилие рассматриваемых беспозвоночных в луговом фитоценозе. В условиях самовосстановления натурбиогеоценоза наибольшим развитием характеризуются гемиэдафические подстилочнопочвенные формы.

\section{Список литературы:}

1. Ветчинников А.А. Влияние известкования, минеральных и органических удобрений на урожайность викоовсяной смеси и горчицы, выращиваемых на нарушенной серой лесной почве // Плодородие. 2010. № 3. С. 4-5.

2. Одум Ю. Экология. М.: Мир, 1986. В 2 т. Т. 2. $376 \mathrm{c}$.

3. Гиляров М.С. Зоологический метод диагностики почв. М.: Наука, 1965. 278 с.

4. Григорьева Т.Г. Роль растительного покрова в формировании почвенной фауны // Почвоведение. 1950. № 11. С. 681-685.

5. Алейникова М.M. Почвенная фауна различных ландшафтов Среднего Поволжья // Почвенная фауна Среднего Поволжья. М.: Наука, 1964. С. 5-51.

6. Безкоровайная И.Н. Участие почвенных беспозвоночных в деструкции органического вещества в лесных экосистемах Средней Сибири // Почвоведение. 2011. № 2. С. 206-214.

7. Грюнталь С.Ю. Почвенная мезофауна таежных буроземов // Почвоведение. 2009. № 11. С. 1374-1382.

8. Камаев И.О. Население почвенной мезофауны в экологических градиентах северной тайги Восточной Фенноскандии: автореф. дис. ... канд. биол. наук. М., 2012. 26 с.

9. Артемьева Т.И. Некоторые закономерности формирования животного населения техногенных агроценозов // Формирование животного и микробного населения агроценозов. М.: Наука, 1982. С. 16-17.

10. Бабенко А.Б. Формирование населения почвообитающих микроартропод на отвалах горной промышленности: автореф. дис. ... канд. биол. наук. М., 1984. $21 \mathrm{c}$.

\section{ECOLOGICAL ASSESSMENT OF REGENERATION ABILITIES OF MICROFAUNISTIC COMPLEX SOIL INVERTEBRATES IN CONDITIONS OF RECULTIVATION TO TECHNOGENIC TRANSFORMED LIGHT GRAY FOREST SOILS}

(C) 2019

Vershinina Irina Valeryevna, candidate of biological sciences, associate professor of Ecological Education and Rational Environmental Management Department

Kozlov Andrey Vladimirovich, candidate of biological sciences, associate professor of Ecological Education and Rational Environmental Management Department Minin Nizhny Novgorod State Pedagogical University (Nizhny Novgorod, Russian Federation)

Abstract. The following paper presents the results of the ecological assessment of the technogenic impact on the number of microfaunistic complex of soil invertebrates in conditions of natural meadow biocenosis. The goal of the 
paper is to assess remediation actions impact on regeneration processes of microfauna community in conditions of technogenic transformed soils. The probes were carried out on gray forest sandy loamy soils of the Nizhny Novgorod Region. Micro arthropod was assessed according to methods admitted in soil zoology with subsequent extractions to laboratories by the Tulgrena-Berleze method with heating up by electro lamps. More than 4100 samples $\left(125 \mathrm{~cm}^{3}\right.$ each) have been analyzed to assess the total number of microfaunistic complex of broken soils. The results were the data reflecting dynamics of oribatides and collembols representatives population change in anthropogenically broken soils. The authors established that a mechanical violation of soil leads to sharp decrease of micro arthropod number. In conditions of technogenic influence the firmness of microfauna makes 17 pieces $/ \mathrm{m}^{2}$. The highest number of small soil invertebrates was established in 2018. The authors emphasize that the number of small terricolous most intensively increases when the soil is partially recultivated.

Keywords: tehnogenic transformed soils; micro fauna; pedobiota; soil invertebrates; micro artropods; collembols; biotope; biocenosis; oribatides; regeneration process; soil invertebrates; recultivation actions; vertical distribution of organisms; stability of soil ecosystem.

УДК 504.062.2 /502.63

DOI 10.24411/2309-4370-2019-12104

Статья поступила в редакцию 16.02.2019

\title{
ЭКОЛОГИЧЕСКАЯ ОЦЕНКА ТЕРРИТОРИИ С УЧЕТОМ ФУНКЦИОНАЛЬНОЙ НЕОДНОРОДНОСТИ ЗЕМЕЛЬ ОТДЕЛЬНЫХ КАТЕГОРИЙ
} (C) 2019

\author{
Глуховская Марина Юрьевна, кандидат технических наук, \\ доцент кафедры экологии и природопользования \\ Евстифеева Татьяна Александровна, кандидат сельскохозяйственных наук, \\ доцент кафедры экологии и природопользования
}

Гривко Елена Васильевна, кандидат педагогических наук, доцент кафедры экологии и природопользования Оренбургский государственный университет (г. Оренбург, Российская Федераияи)

Аннотация. Повсеместная деградация природных экологических систем диктует необходимость установления их предела устойчивости и стабильности, которые, прежде всего, отображаются в изменении свойств компонентов окружающей среды в результате воздействия разнообразных факторов, в первую очередь антропогенных. Устойчивость выражается через коэффициент (Кэурт), определяемый как соотношение площадей территорий под элементами благоприятного и негативного воздействия. Определение коэффициента экологической стабильности (Кэс) подразумевает учет экологической значимости каждого из биотехнических элементов местности. Данная методика предполагает наличие несколько этапов исследований: анализ структуры земельного фонда региона, выявление приоритетных по площади категорий земель, оценку вклада отдельных биотехнических элементов внутри категорий в сохранение экологической устойчивости и стабильности. Исследования проводились на территории Оренбургской области, которая относится к субъектам с преобладанием агропромышленного сектора, отличающимся высокой скоростью роста нарушенных земель. Оценка производилась за период с 2002 по 2016 гг. В ходе исследования выявлено, что в регионе приоритетными по площади являются земли сельскохозяйственного назначения, на их долю приходится 88,5\% от общей площади исследуемой территории. Данная категория земель подлежит, в зависимости от функционального использования, делению на пашни (55,9\%), кормовые угодья (43,5\%), многолетние насаждения $(0,5 \%)$ и прочие земли $(0,1 \%)$. Значение коэффициента стабильности в течение всего периода исследования в среднем составляет 0,36, что на 29,5\% ниже минимальной нормы и характеризует территорию как малостабильную. Максимальное значение показателя устойчивости составляет 0,79 при оптимальном не менее 1 , что позволяет отнести исследуемую территорию к категории «малоустойчивые». Полученные значения изучаемых параметров позволяют сделать выводы о выходе за рамки пределов устойчивости экосистем Оренбургской области и нарушении стабильности их развития. Снизить нагрузку на земельный фонд исследуемого региона позволит дифференцированный подход, на основе системы экологического районирования.

Ключевые слова: земельный фонд; антропогенная преобразованность почв; структура земельного фонда; экологическая значимость биотехнических элементов; экологическое районирование; саморегулирование экосистем; экологическая устойчивость; экологическая стабильность; экостабилизирующая функция земель.

\section{Введение}

Прикладная наука находится в поисках подходов и методик, которые можно использовать для определения экологической устойчивости тех или иных территорий $[1 ; 2]$.

Один из подходов основан на расчете показателя экологической устойчивости региональных территорий (Кэурт).

В зависимости от степени антропогенной преобразованности, различные категории земель неодинаково воздействуют на окружающую среду. Положи- тельный или отрицательный эффект такого воздействия и позволяет спрогнозировать изменение степени устойчивости определенных территорий с точки зрения саморегулирования.

Цель работы: выполнение оценки территории по параметрам экологической стабильности и устойчивости.

\section{Методы и результаты исследований}

Словацким институтом ландшафтной экологии разработана методика определения коэффициента экологической устойчивости территории [3-7], опре- 